Revista Temas Socio Jurídicos

Vol. 38 No 77 Julio - Diciembre de 2019

ISSN: 0120-8578

ISSN electrónico: 2590-8901

\title{
UNIONES MARITALES DE HECHO ATÍPICAS
}

\author{
Antonio Bohórquez Orduz ${ }^{1 *}$
}

Recibido: Julio 6 de 2019

Aprobado: Noviembre 13 de 2019

\section{RESUMEN:}

Los juristas, hasta el momento, suelen predicar que las situaciones de familia que no encajan en las reglas acostumbradas carecen de respuesta en nuestro sistema jurídico; no obstante, surgen conflictos que precisan respuestas y ellas se abren camino con ayuda de los principios constitucionales.

Citar este trabajo como: Bohórquez, A. (2019). Uniones maritales de hecho atípicas. En: Temas Socio-Jurídicos, 38(77), pp. 29-44. DOI: https://doi. org/10.29375/01208578.3735

\section{UNUSUAL COMMON LAW MARRIAGES}

\begin{abstract}
:
Up until now, jurists often claim that family situations that do not adjust to common rules do not have responses in our legal system; however, conflicts arise that require answers and these may be found with the help from constitutional principles.

Keywords: Unusual common law marriages, family, constitutional principles.

1 * El autor es abogado de la Universidad Autónoma de Bucaramanga, profesor en esta misma Institución, Doctor en Derecho de la Universidad Externado de Colombia, magistrado de la Sala Civil-Familia del Tribunal Superior de Bucaramanga, autor de varias obras jurídicas. (Además, el autor es católico creyente, dato que interesará a algunos lectores).
\end{abstract}




\section{UNIÕES ESTÁVEIS ATÍPICAS}

\section{RESUMO:}

Até agora, os juristas costumam pregar que situações familiares que não se enquadram nas regras habituais não têm resposta no nosso sistema jurídico; no entanto, surgem conflitos que exigem respostas e abrem caminho com a ajuda dos princípios constitucionais.

Palavras-Chave: Uniões estáveis atípicas, família, princípios constitucionais.

\section{PRELUSIÓN}

Este artículo es también producto de la investigación que realizamos sobre el instituto unión marital de hecho, recientemente publicada (Bohórquez Orduz, 2019), y con él pretendemos ensayar una respuesta al siguiente problema jurídico:

¿Es viable la aplicación de la actual normativa colombiana sobre unión marital de hecho a las situaciones de familia atípicas que surgen en nuestro país?

\section{LA CUESTIÓN DEL LENGUAJE}

En esta temática, el asunto del lenguaje no es cuestión de poca monta. Como lo denunciamos en su momento (Bohórquez Orduz, 2019, pág. 2), ha sido una tendencia tradicional en el medio colombiano, incluida la jurisprudencia actual de la Corte Suprema de Justicia, la de referirse a las relaciones familiares ajenas al matrimonio con expresiones peyorativas y denigrantes que desdicen de la función que nuestros jueces deben cumplir, al tiempo, que revelan los prejuicios de quienes así se expresan y desconocen que las referencias verbales en términos desobligantes implican vulneración de derechos fundamentales de las personas, en la medida en que atentan contra su dignidad.

Ahora, vale la pena advertirlo, no basta con que la providencia o el texto del que se trate (demanda, ensayo, lo que fuere) anuncie que no se usa determinada expresión en modo peyorativo, pues este asunto no se remedia con un simple aviso, ya que se trata de un fenómeno cultural arraigado en la comunidad colombiana, no por ello tolerable; el propio legislador propendió a la erradicación de ese lenguaje y la Constitución Política de 1991 reforzó aún más tal necesidad.

$\mathrm{Y}$, desde luego, si ese lenguaje es revelador de una tendencia descalificante per se de los posibles derechos de las personas, el problema es mucho más grave de lo que la idea sugiere, pues entonces, no es un simple problema de lenguaje. La palabra concubina y sus derivadas concubinato y concubinario tienen, históricamente, una connotación 
machista, de abominable posesión del hombre sobre la mujer, hoy absolutamente inadmisible.

Con la mejor intención, la sentencia del 22 de junio de 2016 (Corte Suprema de Justicia, Sentencia C SC8225-2016) hace una curiosa distinción según la cual la unión marital de hecho es fenómeno distinto del concubinato y ambas son formas de constituir una familia. La sentencia del 24 de octubre de 2016 (Corte Suprema de Justicia, Sentencia C SC15173-2016) reitera la discutible diferenciación que se aparta, en buena medida, de la voluntad legislativa de dejar de usar ese lenguaje para referirse, precisamente, a la formación de una familia, y de la voluntad del constituyente que abomina del trato discriminatorio. Si la idea del ilustre redactor de la sentencia es la de referirse a uniones de personas que, antes de su relación tuvieron un matrimonio que no ha sido disuelto y cuya sociedad conyugal se mantiene vigente, el propósito es marcadamente peyorativo e injusto, sin proponérselo, pues si ambas familias son ajenas al vínculo matrimonial, si ambas son permanentes, si en ambas hay ayuda y socorro mutuos, no se percibe diferencia alguna para hacer significar, contra legem, que se trata de fenómenos distintos y que el uno es unión marital de hecho, porque no hay impedimento para el matrimonio, y el otro es un simple concubinato. Entonces, es inadmisible la denominación, pues es contraria a nuestro sistema jurídico. No es esto lo que se desprende del artículo 1 de la Ley 54 de 1990. El esfuerzo de la sentencia apunta más bien a sostener la figura de la sociedad de hecho entre concubinarios, creada por la Corte otrora para solucionar un vacío legal que hoy ya no existe, máxime si, como lo dice la Corte, las dos figuras, supuestamente diferentes, se ponen bajo el cobijo protector del artículo 42 de la Constitución Política. Y si la distinción apunta hacia lo que en este ensayo llamamos unión marital atípica, pues la denominación concubinato es completamente inapropiada debido a la connotación histórica de marcado machismo que tiene la expresión, como anteriormente lo dijimos.

\section{EL ELEMENTO MORAL EN LAS DECISIONES JUDICIALES}

Aunque el juez o el magistrado suele negar que su decisión tenga elementos no jurídicos, con frecuencia los tiene, especialmente si el conflicto que hubo de dirimir se halla en esta zona tan subjetiva que corresponde al derecho de familia. La influencia kantiana, especialmente kelseniana, de esa actitud es innegable. Una lectura entre renglones de muchas decisiones judiciales revela no solamente unos prejuicios moraloides ${ }^{2}$ con los que el juez o la jueza se acerca a los conflictos, sino también unas aprensiones que le han sido inculcadas desde posturas machistas y pseudoreligiosas ${ }^{3} \mathrm{y}$ de las cuales, la mayoría de las veces, ni siquiera es consciente.

\footnotetext{
2 La moral -despojada de connotación religiosa- propende a la bondad, a la corrección.

3 Todas las religiones predican el amor por el prójimo y la comprensión. “¿Quién soy yo para juzgar?" es frase del Papa Francisco.
} 
Aunque Kelsen admitía que el juez crea Derecho, pues considera que en caso de vacío legislativo tiene un poder discrecional para decidir, lo cual tiene una innegable repercusión en toda la teoría jurídica de la actualidad (Villar Borda, 2004), este ilustre teórico del Derecho pensaba que la Moral y el Derecho estaban necesariamente separados. Sin embargo, como lo señala Paulson (2000, p. 100), tampoco era partidario Kelsen de una separación absoluta entre el derecho y la moral. Describía, más bien, una vía intermedia, en la cual el derecho, en el momento de producirse la norma (incluida la sentencia), incorporaba en ella elementos morales, los que pasaban a transformarse en derecho. Kelsen (2007 -edición original de 1934) decía que "El derecho se asemeja al rey Midas", convierte en derecho todo cuanto toca, "todo aquello a que el derecho se refiere, toma carácter jurídico" (pág. 284). Se le reprocha el no haber intuido la pretensión de corrección de la decisión judicial e, incluso, de la labor productiva de normas que desarrollan las cortes en todos los niveles, lo cual implica una mayor participación de la moral de la que el ilustre jurista imaginó. No se percató de que el juez, en su labor de dirimir conflictos, siempre estará forzado a realizar valoraciones, explícitas o implícitas, con lo cual, en su determinación será posible detectar elementos de moralidad, cuando el juzgador trata de explicar, aun en los casos en los cuales se equivoca, las razones por las cuales estima razonable su decisión.

Emilio Betti (1975, pág. 435 -edición original de 1949-), por su parte, al tiempo que advierte que la tarea de interpretar se halla mediada por el lenguaje, también prevé que el juzgador jamás hace una simple labor de aplicación de una norma, pues el intérprete al entender un pensamiento que transmite el legislador o un precedente obligatorio, en realidad lo traduce y lo recrea en sus propias categorías mentales (Betti, 1975, pág. $38)^{4}$. En consecuencia, en la tarea de interpretar un texto legal o jurisprudencial o doctrinal siempre es inevitable que un factor subjetivo sea involucrado.

Hans George Gadamer (1991 -edición original de 1960), quien ha marcado también hondas influencias en este devenir neoconstitucionalista de la segunda mitad del siglo XX, habló de precomprensiones humanas; según su parecer, ningún intérprete puede desprenderse de las ideas preconcebidas acerca de un tema y, por consiguiente, acerca del texto mismo, las cuales varían o se afianzan con el desarrollo de la lectura, en un proceso que puede ser infinito. Desde luego, cada intérprete tiene sus precomprensiones (Gadamer, 1991, pág. 331) de acuerdo con su bagaje familiar, cultural, religioso, etc.

Robert Alexy (2002) enseña que una norma jurídica no es un simple texto, pues de un mismo "enunciado normativo" pueden surgir una, dos, 
tres, o muchas normas adscritas (pág. 51); mientras mayor sea la indeterminación, más normas adscritas pueden surgir. En ese sentido, la decisión de un juez en un caso concreto jamás es una simple subsunción de los hechos en una norma, pues este, como corolario de su tarea de juzgamiento, elige una norma adscrita, y tal elección supone un acto de valoración y una pretensión sincera de que es la correcta, lo cual pone de manifiesto una necesaria imbricación entre el derecho y la moral en el proceso mental en comento.

De esta manera, en armonía con estos pensadores, no es posible decirle al juzgador que se despoje de sus convicciones morales, pues, aunque muy convencido nos diga que lo hará, es muy probable que a la postre no lo haga y que, incluso de manera inconsciente, incline su balanza por una decisión inicua solo porque un sector del conglomerado la mirará con buenos ojos, aunque en el fondo la determinación sea, en realidad, alejada del propio sistema jurídico que dice defender, en razón de que vulnera derechos de personas y huella principios constitucionales. La sentencia inicua no puede considerarse acorde con un sistema jurídico como el nuestro. Siguiendo a Alexy (2002), la intervención de la moral tiene hoy plena justificación en el Derecho cuando con ella se busca conseguir la respuesta correcta para un conflicto, es decir, la más acorde con todo el ordenamiento, entendido este como un todo, como un sistema y no como un simple conglomerado de normas escritas; pero no la tiene en el caso contrario, porque, en ese caso, es falsa moral, en los parámetros de toda la comunidad a la cual el juez sirve, sin exclusiones.

\section{CUANDO LA PSEUDOMORALIDAD DE UN SECTOR DEL SISTEMA SOCIAL IMPONE SENTENCIAS INICUAS}

Movida por el peso de cierta influencia social y religiosa, en muchos casos la jurisprudencia de la Corte Suprema de Justicia y de los Tribunales Superiores ha despachado casos con sentencias que suelen ser calificadas como legales (dura lex, dicen), pero que tienen cierto dejo de injusticia, lo cual, por lo menos a partir de la Constitución Política de 1991, no parece en realidad engastado en las normas. Como ya lo hemos mencionado en otro trabajo, la famosa sentencia del 30 de noviembre de 1935, tan celebrada por la propia Corte Suprema de Justicia, contiene una tendencia de injusticia que se mantuvo por décadas, cuyos efectos nocivos aún no cesan, ya que la Corte de entonces, por razones de falsa moral y pseudoreligiosas, no se atrevió a resolver el problema de las parejas de hecho mediante la figura más similar, el matrimonio (para usar en verdad la analogía en todo su esplendor), sino que tomó, como similar, la figura de la sociedad mercantil, de analogía muy lejana, en realidad; y no contenta con ello, endureció sus requisitos por tratarse de una pareja que vivía en unión libre.

Además, en época más reciente, la Corte Suprema de Justicia excluyó de la tipificación que hizo el legislador en 1990 a las parejas que no reúnen 
los requisitos del artículo segundo, postura que corrigió muy débilmente, pues desde la sentencia del 28 de noviembre de 2012 (Corte Suprema de Justicia, Expediente 2006-00173) al menos admite que es posible el reconocimiento de la unión marital de hecho, pero sigue desconociendo la posibilidad de que las parejas que no encajan en ese artículo segundo tengan la oportunidad de probar que sí tuvieron una sociedad patrimonial derivada de su relación familiar, aunque no estén bajo el cobijo de la presunción, pues la Corte Suprema de Justicia entiende no que carecen de presunción (que es lo que dice la norma) sino que carecen de derecho, interpretación del todo absurda que la Corte ha mantenido hasta el momento.

Si eso sucedió con parejas que el propio sistema normativo encuentra como normales (compuestas por un hombre y una mujer) ya se imagina el lector qué podía ocurrir con otro tipo de uniones maritales atípicas, es decir, que no encajan en las normas, pues no reúnen los requisitos puestos en la ley (heterosexualidad, convivencia permanente y singularidad), pero sí encajan en un concepto socio jurídico de familia (por el afecto, la cohesión, la convivencia, la ayuda y el trato), y cuando además de la relación entre los integrantes de la unión marital ha surgido una masa patrimonial gracias al trabajo, la ayuda y el socorro mutuos que convoca partición. El calificativo de atípicas solo atañe al fenómeno jurídico innegable de que no aparecen reguladas en la ley; de ninguna manera ha de tomarse como una expresión peyorativa. Simplemente, el legislador no se ha ocupado de ellas.

Varias hipótesis de uniones atípicas nos vienen a la mente, la primera de las cuales es la de parejas integradas por personas del mismo sexo, cuyos derechos eran denegados en el pasado, pero que hoy, por fortuna, no solo la Corte Constitucional sino también la Corte Suprema de Justicia reconocen sin ambages. Que en el pasado se les denegaba todo derecho es claro; valga como ejemplo la sentencia del 13 de diciembre de 2011 (Corte Suprema de Justicia, Expediente 2007-0425) en que la Corte argumenta, para denegar derechos a personas que constituyeron uniones maritales de hecho con alguien de su mismo sexo (cuando ya la Corte Constitucional había reconocido la posibilidad en abstracto), que la sentencia $\mathrm{C}$ 075 de 2007 (Corte Constitucional, Sentencia C-075 de 2007) no puede aplicarse hacia el pasado, cuando esta última sentencia citada no es de inexequibilidad de norma alguna, sino una sentencia integradora que indica cómo debe entenderse la ley, a la luz de la Constitución Política de 1991, lo que implica plena aplicación de la norma, desde la puesta en vigencia de la Constitución; no obstante, la Corte Suprema de Justicia cayó en la falacia de afirmar que solo aplicaba hacia el futuro, lo que significaría que para esa Corte la Constitución Política tendría ese condicionamiento de aplicación, lo cual es absurdo. Si la norma es exequible y, conforme con la Constitución, debe entenderse que aplica para todos los momentos en que coincida la vigencia de la norma con la vigencia de la Carta. Además, el futuro no se refiere al momento en que ocurrieron los hechos sino al 
momento en que el juez los valora, pues es problema ligado con los derechos fundamentales de las personas; y ya para este momento estaba vigente la sentencia.

En ocasiones, la exégesis de una sentencia puede ser tan nociva como la exégesis de la ley, salvo cuando la exégesis literal del enunciado sea una forma de garantismo. La sentencia citada de la Corte Suprema fue retardataria e injusta. Sin embargo, años más tarde la Corte Suprema de Justicia ha reconocido los derechos de quienes integran parejas y son del mismo sexo, como lo hizo en las sentencias del 31 de julio de 2014 (Corte Suprema de Justicia, Expediente 2008-01147), 14 de diciembre de 2015(Corte Suprema de Justicia, Expediente 2010-0026) y 12 de febrero de 2018 (Corte Suprema de Justicia, Expediente 2008-00331), las cuales han dejado en el pasado la criticada sentencia, aunque mantienen el criterio de la vigencia la sentencia C 075 de 2007, que nos luce muy discutible.

No obstante, los problemas subsisten en relación con parejas de personas heterosexuales (que la Corte Suprema de Justicia toma como atípicas (y en sus esquemas mentales, como carentes de derechos) porque no reúnen los requisitos del artículo segundo de la ley 54 (que la Corte aún no percibe como requisitos de una presunción, que es lo que la norma dice literalmente, con lo que, como hemos indicado en otro momento, la norma es procesal y no sustancial). Y con mayor razón persisten las dificultades en relación con situaciones de familia aún más diversas, como las relaciones permanentes y consentidas de una mujer con varios hombres (escasa) o de un hombre con varias mujeres (también escasa, pero más común), o de tres o más personas del mismo sexo, que conviven de manera permanente y que, por no tener el requisito de la singularidad, no encajan en la tipificación legal de la unión marital de hecho convencional, pero podrían verse involucrados en conflictos judiciales ante disputas de diversa índole respecto de intereses patrimoniales. Algo de delantera, como se sabe, ha tomado el derecho laboral en estos temas patrimoniales, al admitir la posibilidad de decretar pensiones compartidas, tanto en lo que atañe con sobrevivientes, como respecto de sustituciones pensionales. Recientemente el Tribunal de Medellín (Expediente 2015-01955) reconoció pensión de sobrevivientes a dos varones que convivían con un tercero, también hombre, quien falleció. La determinación es plausible y, sin duda, puede insertarse en este estudio en el que a ese tipo de relaciones familiares denominamos uniones maritales de hecho atípicas.

Nótese que la exigencia de la heterosexualidad, tanto en el matrimonio, como en parejas de hecho, no ha sido derogada, ni mucho menos declarada inexequible. Tampoco lo han sido los requisitos adicionales de la unión marital (convivencia permanente y singularidad). Sin embargo, las dos Cortes, finalmente, coinciden en el reconocimiento de derechos a los integrantes de parejas conformadas por personas del mismo sexo. La ati- 
picidad es obvia, pero, desde luego, las determinaciones completamente plausibles. Y en este tema se adelantaron las Cortes al legislador, que aún no regula estos puntos. Ahora, si fue posible llegar a estos resultados en relación con parejas homoparentales, no se explica este autor porqué las Cortes no han podido superar sus prejuicios frente a otro tipo de situaciones atípicas respecto de las cuales puede ser entendible que los magistrados tengan sus aprensiones morales, como puede tenerlas cualquier persona, pero, no es admisible que no puedan sobreponerse a ellas para entender y respetar las decisiones de vida de otras personas, especialmente para reconocerles los derechos que el sistema jurídico ofrece también para esas personas, por más inusual que sea su situación.

La tarea del juzgador no es la de hacer un reproche moral, fundado o no; mucho menos este funcionario puede pretender imponer a los justiciables sus propias convicciones morales; su tarea es la de aplicar el sistema jurídico, pese a que al propio juez le parezca inarmónico el evento con su moral personal. Y aunque la jurisprudencia es fuente de derecho, conforme con la teoría del precedente vinculante, las sentencias que se hallen en desarmonía con los principios constitucionales deben ser combatidas $y$, en parte, esa es tarea de la academia.

Uno de los casos que en este terreno tan espinoso puede citarse es el de la sentencia del 19 de diciembre de 2005 (Corte Suprema de Justicia, Expediente 7756) en que la Corte resolvió en casación el conflicto propuesto por Martha contra Rigoberto, en el que ella había solicitado en su demanda que se declarara una "sociedad patrimonial de hecho" formada entre ellos desde junio de 1975 por más de veinte años, pues entre las partes existió vida marital, fruto de la cual tuvieron un hijo, al tiempo que, con el aporte del esfuerzo personal de la demandante, obtuvieron una pequeña fortuna familiar. El demandado, para defenderse, adujo que entre él y la demandante no podía haberse formado una unión marital de hecho ya que son padre e hija; para probar esto, aportó un registro de nacimiento sentado por él, cuando su hija contaba con 15 años de edad. El Juzgado de primera instancia denegó las pretensiones al reconocer que las excepciones del demandado eran fundadas. El Tribunal de Cundinamarca revocó la sentencia y declaró la sociedad patrimonial tal y como había sido pedida, al estimar que la prueba del alegado estado civil entregada por el demandado no era aceptable como tal.

El Tribunal consideró que "no habiéndose notificado el reconocimiento en la forma ordenada en la ley, más aún, habiéndolo repudiado la reconocida, el mismo no puede tener efectos, pues tiene su fundamento en un hecho ilíito, la suposición de un estado civil" (Tribunal Superior de Cundinamarca, Sala Civil Familia, sentencia del 9 de junio de 1999), con lo cual, en su sentir, no estaba probada la relación de parentesco alegada entre la demandante y el demandado y, por consiguiente, era posible declarar que entre ellos existió la unión marital 
de hecho alegada y, por consiguiente, la sociedad patrimonial, ya que el demandado era viudo para cuando se inició la convivencia. Además, consideró el Tribunal que, de entenderse que el demandado es el padre de la demandante, el punto resultaba irrelevante si se considera que, así como en el supuesto de que se hubiesen casado, de toda suerte tendrían sociedad conyugal aunque el matrimonio fuese nulo, en razón de lo dispuesto por el artículo 1820, numeral 4, del Código Civil (que prevé la ausencia de sociedad conyugal sólo para el evento en que la nulidad del matrimonio se origina en la existencia de otro matrimonio anterior), igualmente debe considerarse que es viable la sociedad patrimonial, aunque para los pretendidos compañeros permanentes existiese impedimento legal para casarse entre sí, si además se tiene en cuenta que el artículo 1820 del Código Civil es norma de las remitidas por el artículo 7 de la Ley 54 de 1990.

El demandado acudió en casación y la Corte Suprema de Justicia casó la sentencia impugnada del Tribunal de Cundinamarca en razón del error de valoración probatoria que cometió el Tribunal frente al mentado estado civil, que en realidad sí estaba probado, pues el acto del demandado no fue suposición del estado civil sino reconocimiento de paternidad, ya que el acto de 1959 prueba la maternidad y, el de 1977, la paternidad, con lo cual no es cierto que los dos certificados muestren estados civiles contrapuestos, amén que no aparece prueba alguna de que la demandante hubiese rechazado el reconocimiento de paternidad, hecho que supuso el Tribunal. Ante tal hallazgo, la Corte casó la sentencia y, en la tarea de emitir la sentencia sustitutiva, consideró que, al estar demostrado el vínculo filial que une a Martha y a Rigoberto, entre los dos no podía haberse formado una unión marital de hecho porque, afirma, luego de una erudita relación de antiguas normativas sobre el concubinato, que la unión de hecho incestuosa no puede generar sociedad patrimonial entre la pareja ya que sería tanto "como aseverar que, simultáneamente, una misma conducta sea permitida por el ordenamiento y a la vez reprimida por éste, lo que es inadmisible en nuestro sistema legal que reclama la coherencia entre sus instituciones" (Corte Suprema de Justicia, sentencia del 19 de diciembre de 2005).

La Corte, en la citada providencia, invoca con énfasis el indiscutible rechazo del ordenamiento jurídico colombiano al incesto", así como que "la descalificación de las relaciones incestuosas ha sido una constante social que ha obedecido a ancestrales patrones culturales instituidos en nuestro país" " (Corte Suprema de Justicia, sentencia del 19 de diciembre de 2005), para concluir que de ese tipo de conductas no pueden derivarse derechos, con lo que la demandante carece absolutamente de los invocados en sus pretensiones. En consecuencia, confirmó el fallo desestimatorio emitido en primera instancia.

5 No puede este investigador evitar preguntarse: ¿acaso la Corte habría negado derechos al hijo común que estas personas tuvieron, bajo el argumento de que el incesto no puede producir efectos jurídicos? 
La providencia no solamente es controversial sino muy lamentable. No solo porque los magistrados juzgaron orientados por sus prejuicios pseudomoralistas y sus convicciones pseudoreligiosas y, lo que es más grave, imbuidos de un inconsciente machismo disfrazado de erudición, sino porque la decisión tiene errores de tipo jurídico, que, para comprenderlos, basta enunciarlos como en seguida haremos:

1. El reproche que la Corte hace al Tribunal de Cundinamarca es infundado (respecto de asimilar la unión marital al matrimonio para dar aplicación al artículo 1820 del Código Civil y entender que, así como en el matrimonio hubiese existido sociedad conyugal a pesar del vínculo que haría nulo el matrimonio, igual era posible que la unión marital en las mismas condiciones generase sociedad patrimonial). La asimilación no la hace el Tribunal; la hizo el propio legislador, puesto que el artículo 7 de la Ley 54 de 1990 remite a las normas civiles y el artículo 1820 es una de las remitidas;

2. Como se puede notar en la narración que la propia Corte hace del caso, la demandante jamás invocó en su demanda la relación padre e hija que entre las partes existía; ese hecho fue asomado por el demandado como defensa, detalle que pasa ignorado por la Corte;

3. la demandante nunca pidió declaratoria de unión marital de hecho sino, apenas, de la sociedad patrimonial de hecho, con lo cual la Corte hubiese podido construir la figura de la unión marital de hecho atípica, o, al menos, interpretar la demanda y entender que se le pedía sociedad de hecho (no hubiese sido la solución correcta, tampoco, a nuestro juicio, -por eso decimos al menos-, pues al resolver el conflicto como si fuese uno de derecho mercantil, también se sanciona a la víctima, ya que la discusión giraría en torno de aportes, distribución de utilidades, reparto del patrimonio en proporción a los aportes -para lo cual se precisa un dictamen pericial-, affectio societatis, etc.);

4. el demandado explotó, para defenderse, su propia falta, y la Corte la aceptó como excepción válida contra el principio general de derecho que indica que nadie puede sacar provecho de su propia culpa;

5. la demandante fue tomada como mujer por su propio padre cuando era menor de edad, lo cual implica, de suyo, violencia parental, además de violencia de género, que los magistrados reprochan, pero solo en abstracto, pues el victimario, como vimos, se beneficia jurídicamente de su acto vituperable, mientras la castigada es la víctima;

6. los magistrados ignoraron su deber de proteger a la mujer de la violencia de género, no obstante que ya para entonces estaban vigentes normas como la Ley 51 de 1981, aprobatoria de la "Convención sobre la eliminación de todas las formas de discriminación contra 
la mujer", adoptada por la Asamblea General de las Naciones Unidas en 1979 y la Ley 248 de 1995, aprobatoria de la "Convención Internacional para prevenir, sancionar y erradicar la violencia contra la mujer", suscrita en la ciudad de Belem Do Para; y

7. la sentencia sanciona a la víctima y premia al victimario, con lo cual, se torna más evidente y notoria la carga de violencia parental y machista que hay en esta historia que los magistrados corroboran y denuncian ante la Fiscalía, pero bendicen con una decisión que comporta aún mayor violencia contra la mujer.

En honor a la verdad, hay que recordar que esta es una sentencia de 2005; que, por entonces, la Corte aún pensaba que la unión marital de hecho no era un estado civil, que ni siquiera asomaba por los estrados judiciales la posibilidad de que la figura se mirara como aplicable a parejas conformadas por persona del mismo sexo y que, aunque ya había reconocido la retrospectividad de la Ley 54 de 1990, esa discusión se hallaba aún muy fresca.

La Corte perdió esta oportunidad de demostrar que el sol brilla para todos; que el legislador es sabio cuando ordena usar la analogía, los principios constitucionales, los principios generales de derecho y la equidad para resolver esos conflictos que el legislador no ha contemplado; que la Ley 54 de 1990 no es excluyente de tales conflictos, pues ninguna de sus normas lo indica y, en consecuencia, puede usarse para relaciones de pareja atípicas ${ }^{6}$, solo con la advertencia de que el artículo segundo de la ley no les es aplicable, ya que tales uniones, no encajan en las previsiones de la presunción y, por tanto, quien actúa como parte demandante tiene una mayor carga probatoria para demostrar el trabajo, la ayuda y el socorro de los cuales se derivó una masa de bienes a la que tiene derecho.

\section{CONCLUSIONES}

Primera: en las relaciones interpersonales y familiares surgen muchas situaciones y conflictos para los cuales el sistema normativo escrito no ofrece respuesta.

Segunda: una de tales situaciones es la que podemos denominar unión marital de hecho atípica, la cual tiene muchas variantes, todas hoy desprovistas de consecuencias jurídicas por un error de entendimiento de la ley por parte de los juzgadores, que necesariamente va siendo superado.

6 No puede desconocerse que la demandante habría podido pedir sociedad de hecho -a la usanza anterior a la ley- o la Corte habría podido entender así la demanda, pues la pretensión no fue de unión marital; prefirió ignorar esa posibilidad, que, como hemos demostrado en nuestra obra citada (Bohórquez Orduz, 2019), no es una salida justiciera; pero sí preferible a la adoptada por la Corte. Y hubiese podido también la demandante pedir una indemnización por el vejamen de que fuera víctima, que, en realidad, hubiese podido demandar simultáneamente, pues no son derechos incompatibles, pero no lo hizo. 
Tercera: la Ley 54 de 1990 (que jamás estableció entre sus reglas alguna excluyente) junto con los principios constitucionales y los principios generales de derecho, por analogía, puede contribuir a solucionar ese tipo de conflictos $^{7}$. La inaplicación al caso de la presunción del artículo 2 de la mentada ley hace parte del mismo bloque de consecuencias jurídicas, ya que también hay uniones maritales de hecho típicas a las cuales no se aplica la mentada presunción.

Cuarta: entre las uniones maritales de hecho atípicas podría haber relaciones reprobables, desde el punto de vista penal (como el incesto del caso analizado); solo que, en tales hipótesis, el victimario jamás puede reclamar derechos de la relación; pero, no habría razón jurídica alguna para sancionar también a la víctima. El hecho, vituperable y todo, ya ocurrió, y al juez civil le corresponde dar una respuesta justa al conflicto. La justicia penal se encargará de lo que le compete. La crítica que este trabajo hace a la sentencia de 2005 de la Corte Suprema de Justicia jamás debe entenderse como que abogamos por la legalización del incesto; bien hizo la Corte al emitir compulsas con destino a la Fiscalía General de la Nación, pues es claro que el demandado cometió un delito. Lo que nos parece reprobable es la sanción de la Corte contra la víctima.

Quinta: que en estos conflictos no sea aplicable la presunción de existencia de la sociedad patrimonial no significa que las personas carecen de derechos sustanciales, puesto que sí tienen derecho a demostrar los hechos que no se presumen.

\section{REFERENCIAS BIBLIOGRÁFICAS}

Alexy, R. (2002). Teoría de los Derechos Fundamentales. Madrid: Centro de Estudios Políticos y Constitucionales.

Betti, E. (1975). Interpretación de la ley y de los actos jurídicos. Madrid: Editorial Revista de Derecho Privado.

Bohórquez Orduz, A. (2019). Unión marital de hecho. Una línea jurisprudencial inconclusa. Bogotá: Ediciones Doctrina y Ley.

Gadamer, H. G. (1991). Verdad y método. Fundamentos para una hermenéutica filosófica. Salamanca: Ediciones Sígueme.

Kelsen, H. (2007). Teoría pura del Derecho. México: Porrúa.

Paulson, S. (2000). Fundamentación crítica de la doctrina de Hans Kelsen. Bogotá: Universidad Externado de Colombia.

7 El criterio exégeta según el cual, si la ley no menciona un derecho lo negó, no es correcto. Solo significa que el redactor de la norma no lo tuvo en mente, o que se trataba de un hecho aún ignorado por el conocimiento humano, o que aún no generaba conflictos. En cada caso, el juez debe encontrar la respuesta correcta, consultando el sistema jurídico como un todo. 
Villar Borda, L. (Ed.). (2004). Hans Kelsen 1881 - 1973. Bogotá: Universidad Externado de Colombia.

\section{JURISPRUDENCIA}

\section{COLOMBIA. CORTE CONSTITUCIONAL:}

Sentencia C 075 de 07 de febrero de 2007. Expediente D-6362. M.P. Rodrigo Escobar Gil.

Sentencia C 811 de 03 de octubre de 2007. Expediente D-6749. M.P. Marco Gerardo Monroy Cabra.

Sentencia C 336 de 16 de abril de 2008. Expediente D-6947. M.P. Clara Inés Vargas Hernández.

Sentencia C 798 de 20 de agosto de 2008. Expediente D-7177. M.P. Jaime Córdova Triviño.

Sentencia C 029 de 28 de enero de 2009. Expediente D-7290. M.P. Rodrigo Escobar Gil.

Sentencia T 911 de 07 de diciembre de 2009. Expediente T-2.324.790. M.P. Nilson Pinilla Pinilla.

Sentencia C 100 de 23 de febrero de 2011. Expediente D-8199. M.P. María Victoria Calle Correa.

Sentencia C 283 de 13 de abril de 2011. Expediente D-8112. M.P. Jorge Ignacio Pretelt Chaljub.

Sentencia C-577 de 26 de julio de 2011. Expedientes acumulados D-8367 y D-8376. M.P. Gabriel Eduardo Mendoza Martelo.

Sentencia T 717 de 22 de septiembre de 2011. Expediente T- 3066688. M.P. Luis Ernesto Vargas Silva.

Sentencia SU 617 de 28 de agosto de 2014. Expediente T-2597191. M.P. Luis Guillermo Guerrero Pérez.

Sentencia C-071 de 18 de febrero de 2015. Expediente D-10315. M.P. Jorge Iván Palacio Palacio.

Sentencia C 683 de 04 de noviembre de 2015. Expediente D-10371. M.P. Jorge Iván Palacio Palacio.

Sentencia C 193 de 20 de abril de 2016. D-10985. M.P. Luis Ernesto Vargas Silva.

Sentencia SU 214 de 28 de abril de 2016. Expediente T- 4.167.863. M.P. Alberto Rojas Ríos. 


\section{COLOMBIA. CORTE SUPREMA DE JUSTICIA:}

Sentencia de 30 de noviembre de 1935. Gaceta XLII, p. 476 y s. M.P. Eduardo Zuleta Ángel.

Sentencia de 10 de septiembre de 2003. Expediente 7603. M.P. Manuel Isidro Ardila Velásquez.

Sentencia de 28 de octubre de 2003. Expediente 7007. M.P. Cesar Julio Valencia Copete.

Sentencia de 27 de junio de 2005. Expediente 7188. M.P. Pedro Octavio Munar Cadena.

Sentencia de 19 de diciembre de 2005. Expediente 7756. M.P. Pedro Octavio Munar Cadena.

Sentencia SC268 de 28 de octubre de 2005. M.P. Carlos Ignacio Jaramillo Jaramillo.

Sentencia del 4 de septiembre de 2006. Expediente 1998-00696. M.P. Edgardo Villamil Portilla.

Sentencia de 13 de diciembre de 2011. Expediente 2007-0425. M.P. Fernando Giraldo Gutiérrez.

Sentencia de 28 de noviembre de 2012. Expediente 2006-00173. M.P. Ruth Marina Díaz Rueda.

Sentencias de 31 de julio de 2014. Expediente 2008-01147. M.P. Ruth Marina Díaz Rueda.

Sentencia de 14 de diciembre de 2015. Expediente 2010-0026. M.P. Fernando Giraldo Gutiérrez.

Sentencia C SC8225-2016 de 22 de junio de 2016. Radicado 00129. M.P. Luis Armando Tolosa Villabona.

Sentencia C SC15173-2016 de 24 de octubre de 2016. Radicado 0069. M.P. Luis Armando Tolosa Villabona.

Sentencia de 12 de febrero de 2018. Expediente 2008-00331. M.P. Aroldo Wilson Quiroz Monsalvo.

\section{LEGISLACIÓN}

\section{COLOMBIA}

Código Civil de los Estados Unidos de Colombia. Adoptado por la Ley 84t de 1873. Disponible en: http://www.suin-juriscol.gov.co/ viewDocument.asp? ruta $=$ Leyes $/ 1827111$. 
Código Civil. Adoptado por la Ley 57 de 1887. Disponible en:https://www. cancilleria.gov.co/sites/default/files/Normograma/docs/codigo civil.htm.

Código de la Infancia y la Adolescencia. Ley 1098 de 2006. Diario Oficial No. 46.446 de 8 de noviembre de 2006. Disponible en: https:// www.cancilleria.gov.co/sites/default/files/Normograma/docs/ ley 1098 2006.htm\#82.

Código General del Proceso. Adoptado por la Ley 1564 DE 2012. Diario Oficial No. 48.489 de 12 de julio de 2012. Disponible en: https:// www.cancilleria.gov.co/sites/default/files/Normograma/docs/ ley_1564_2012.htm.

Código Penal. Adoptado por la Ley 599 DE 2000. Diario Oficial No. 44.097 de 24 de julio del 2000. Disponible en: https://www.cancilleria. gov.co/sites/default/files/Normograma/docs/ley_0599_2000.htm

Ley 57 de 1887. Sobre adopción de códigos y unificación de la legislación nacional. Diario Oficial No. 7.019 del 20 de abril de 1887. Disponible en: https://www.cancilleria.gov.co/sites/default/files/ Normograma/docs/ley 0057 1887.htm.

Ley 153 de 1887. Por la cual se adiciona y reforma los códigos nacionales, la ley 61 de 1886 y la 57 de 1887. Diarios Oficiales Nos. 7.151 y 7.152, del 28 de agosto de 1887. Disponible en: https://www.cancilleria. gov.co/sites/default/files/Normograma/docs/ley_0153_1887.htm.

Ley 51 de 1981. Por medio de la cual se aprueba la "Convención sobre la eliminación de todas las formas de discriminación contra la mujer", adoptada por la Asamblea General de las Naciones Unidas el 18 de diciembre de 1979 y firmado en Copenhague el 17 de julio de 1980. Disponible en: http://www.suin-juriscol.gov.co/viewDocument. asp?ruta $=$ Leyes $/ 1605470$.

Ley 54 de 1990. Uniones maritales de hecho y régimen patrimonial. Diario Oficial No. 39615 del 31 de diciembre de 1990. Disponible en: http://www.suin-juriscol.gov.co/viewDocument. asp? ruta $=$ Leyes/1607782. Ley 100 de 1993. Por la cual se crea el sistema de seguridad social integral. Disponible en:http://www. suin-juriscol.gov.co/viewDocument.asp?ruta=Leyes/1635955.

Ley 248 de 1995. Por medio de la cual se aprueba la Convención Internacional para prevenir, sancionar y erradicar la violencia contra la mujer, suscrita en la ciudad de Belem Do Para, Brasil, el 9 de junio de 1994. Disponible en: http://www.secretariasenado.gov.co/senado/ basedoc/ley_0248_1995.html. 
Ley 294 de 1996. Por la cual se desarrolla el artículo 42 de la Constitución Política y se dictan normas para prevenir remediar y sancionar la violencia Intrafamiliar. Disponible en: http://www.suin-juriscol. gov.co/viewDocument.asp? ruta=Leyes/1657714.

Ley 979 de 2005. Modificó la Ley 54 de 1990. Diario Oficial No. 45982 de 27 de julio de 2005. Disponible en:http://www.suin-juriscol.gov. co/viewDocument.asp?ruta $=$ Leyes/1672162.

Ley 1257 de 2008. Por la cual se dictan normas de sensibilización, prevención y sanción de formas de violencia y discriminación contra las mujeres. Disponible en: http://www.secretariasenado. gov.co/senado/basedoc/ley_1257_2008.html.

Ley 1361 de 2009. Por medio de la cual se crea la Ley de Protección Integral a la Familia. Disponible en: http://www.suin-juriscol.gov.co/ viewDocument.asp? ruta $=$ Leyes $/ 1678084$

Ley 1857 de 2017. Por medio de la cual se modifica la Ley 1361 de 2009 para adicionar y complementar las medidas de protección de la familia. Disponible en:http://www.suin-juriscol.gov.co/ viewDocument.asp? ruta $=$ Leyes $/ 30032737$. 